Original Research Paper

\title{
Infiltration of Nanoparticles into Porous Binder Jet Printed Parts
}

\author{
${ }^{1}$ Amelia Elliott, ${ }^{2}$ Sarah AISalihi, ${ }^{3}$ Abbey L. Merriman and ${ }^{4}$ Mufeed M. Basti \\ ${ }^{1,3}$ Manufacturing Demonstration Facility, Oak Ridge National Laboratory, Oak Ridge, Tennessee, USA \\ ${ }^{2}$ Department of Chemical Engineering, North Carolina A\&T University, Greensboro, North Carolina, USA \\ ${ }^{4}$ Department of Chemistry, North Carolina A\&T University, Greensboro, North Carolina, USA
}

Article history

Received: 02-26-2016

Revised: 01-03-2016

Accepted: 01-03-2016

Corresponding Author:

Mufeed M. Basti

Department of Chemistry, North

Greensboro, North Carolina, USA

Email: basti@ncat.edu
Carolina A\&T University,

\begin{abstract}
The densification of parts that are produced by binder jetting Additive Manufacturing (AM; a.k.a. "3D Printing") is an essential step in making them mechanically useful. Increasing the packing factor of the powder bed by incorporating nanoparticles into the binder has potential to alleviate the amount of shrinkage needed for full densification of binder jet parts. In this study we present preliminary data on the use of 316L Stainless Steel Nanoparticles (SSN) to densify 316L stainless steel binder jet parts. Aqueous solutions of Diethylene Glycol (DEG) or Ethylene Glycol (EG) were prepared at different DEG/water and EG/water molar ratios; $\mathrm{pH}$ of the solutions was adjusted by the use of $0.10 \mathrm{M}$ sodium hydroxide. Nanoparticles were suspended in a resulted solution at a volume percentage of $\mathrm{SSN} /$ solution at $0.5 \%$. The suspension was then sonicated for thirty minutes. One milliliter of the suspension was added stepwise to a sintered, printed disk with the dimensions: $(\mathrm{d}=10 \mathrm{~mm}, \mathrm{~h}=3 \mathrm{~mm})$ in the presence of a small magnet. The 3D part was then sintered again. The increase in the mass of the 3D part was used as indication of the amount of nanoparticles that diffused in the 3D part. This mass percent increase was studied as a function of $\mathrm{pH}$ of the suspension and as function DEG/water molar ratio. Unlike EG, data show that change in $\mathrm{pH}$ affects the mass percent when the suspension was made with DEG. Optical analysis of the discs' cross sections revealed trends metallic densities similar to trends in the data for mass increase with changing $\mathrm{pH}$ and water molar ratio.
\end{abstract}

Keywords: Nanoparticles, Additive Manufacturing, 3D Printing, Metal Powder

\section{Introduction}

Additive Manufacturing (AM; a.k.a. "3D Printing") has now many industrial applications such as in aerospace, in medical and in engineering and scientific fields (Leukers et al., 2005; Hockaday et al., 2012). AM of metals typically starts with a with metal powder and shapes the powder feedstock in a number of ways such as direct metal laser sintering (Khaing et al., 2001), selective laser sintering (Silva et al., 2008) and binder jetting (Allen and Sachs, 2000). In the latter method, layers of metal powder are spread and binder is selectively deposited via inkjet until the $3 \mathrm{D}$ part is built according to the design. After deposition, the entire print bed is heated to $200^{\circ} \mathrm{C}$ to cure the binder and solidify the printed shape. The resulting "green" printed shape, also called the skeleton, can be removed from the powder bed and set up for infiltration and sintering.

Because of the low cost of the technology and high throughputs, binder jetting has the potential to surpass many other metal AM processes in utility for industrial applications. However, a major challenge for binder jet $\mathrm{AM}$ is the porosity of the printed part and the subsequent inability to reach full density with a single alloy without significant shrinkage and warpage. For typical powders, the density of the green part is almost $60 \%$ by volume while the other $40 \%$ is open porosity. The fundamental cause for the low density of the green parts is the packing factor of the powder feedstock. Increasing the packing factor of the feedstock powder by filling the void space with 
smaller particles means that objects with densities up $86.8 \%$ can be printed (Rahaman, 2003).

Potentially, utilizing nanoparticles will not only fill the void space but also act as a sintering aid (Koparde and Cummings, 2008). The incorporation of metal nanoparticles in AM has a great interest to researchers since nanoparticles can bring the multi-functionality aspect, such as thermal and electric conductivity, to AM (Crane et al., 2005). It was also shown that adding nanomaterials to AM can improve mechanical properties, lower sintering temperatures and improve dimensional accuracy (Bai et al., 2007; Cutler et al., 1957). One of the first reports on using metal nanoparticles in AM was by Crane et al. (2005) where iron nanoparticles (diameter 7$10 \mathrm{~nm}$ ) were used to improve the quality of 410 Stainless Steel (SS) 3D parts where the particle size of the SS was 63-90 $\mu \mathrm{m}$. The application of nanoparticles was repeated to increase the quantity of the deposited nanoparticles and the work showed that applying the nanoparticles reduced both creep and deflection of the AM.

The ideal scenario for nanoparticle delivery is suspending the nanoparticles within the binder itself and as the binder is deposited via inkjet into the powder bed, the nanoparticles are deposited as well. As a preliminary step to determine the effect of the nanoparticles, in this study we investigate the infiltration of $316 \mathrm{~L}$ stainless steel $3 \mathrm{D}$ parts by $316 \mathrm{~L}$ nanoparticles. It is hypothesized that the dispersion of the nanoparticles within the liquid carrier affects the amount of material delivered to the print. Stainless steel nanoparticles were added to binder jet printed stainless steel skeletons via suspending the particles in water mixed with two different liquid polymer carriers and depositing drop-wise. The $\mathrm{pH}$ of the liquid polymer as well as the polarity determines the stability and dispersion of the suspension. The samples were sintered and measured for increases in mass and density to determine the effectiveness of the infiltration technique.

\section{Experimental Program}

\section{Methodology}

Ethylene Glycol (EG) or Polyethylene Glycol (PEG) are used as binder in binder jetting AM (Hockaday et al., 2012). PEG is a homo copolymer that comprises two or more identical subunits (glycols) that are linked by covalent bonds (Lee et al., 2003) (ether bond: R-O-R'). PEG is also frequently used in binder jetting that uses ceramics as the skeleton material (Ekka, 2012). Halidi and
Abdullah (2012) have studied the effects of polyethylene glycol on Hydroxyapatite Powder (HAP)-binder system for AM applications. Table 1 shows the physical properties of ethylene glycol and different polyethylene glycol polymers.It includes: Monoethylene Glycol (MEG); Diethylene Glycol (DEG); Triethylene Glycol (TEG); and Tetraethylene Glycol (TETRA EG). The data was obtained from The Dow Chemical Company website.

L-grade 316L Stainless Steel Nanoparticles (SSN) (60$80 \mathrm{~nm}$ ) were purchased from SkySpring Nanomaterials, Houston, TX, USA. The composition of SSN as supplied by the manufacturer is $\mathrm{Fe} 62.045-72 \%$, Cr 16-18\%, Ni 10$14 \%$, Mo 2-3\%, Mn 2\%, N 0.1\%, S 0.03\%, C 0.03\%, Si $0.75 \%$ and $\mathrm{P} 0.045 \%$. Sodium hydroxide was purchased from Fisher Scientific, New Jersey, USA and used with no further purification. Ethylene Glycol (EG) and Diethylene glycol (DE) were purchased from ExOne Company, North Huntingdon, PA, USA. The solutions of deionized water/Ethylene Glycol (EG) and deionized water/Diethylene Glycol (DEG) were made at EG/water and DEG/water molar ratios between $1 / 1$ and $1 / 12$. The $\mathrm{pH}$ was altered between the range of 8 and 14 by the dropwise addition $0.10 \mathrm{M} \mathrm{NaOH}$ solution and the $\mathrm{pH}$ was monitored using a Sper Scientific 860031 Benchtop pH meter. The concentration of SSN in the EG/water and $\mathrm{DEG} /$ water solutions was maintained at $0.175 \mathrm{~g} \mathrm{SSN}$ and $4.22 \mathrm{~mL}$ of $\mathrm{EG} / \mathrm{H}_{2} \mathrm{O}$ or $\mathrm{DEG} / \mathrm{H}_{2} \mathrm{O}$ solution. The $\mathrm{SSN}$ suspension was then placed in a $10 \mathrm{~mL}$ conical tube and the tube was immersed in a bath sonicator for $30 \mathrm{~min}$ at room temperature to improve the dispersion of SSN.

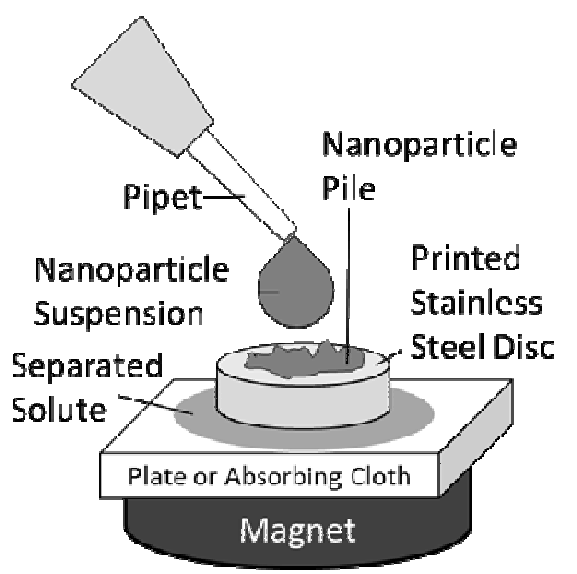

Fig. 1. Experimental setup and subsequent separation of the suspension

Table 1. Physical properties of ethylene glycol and different polyethylene glycol polymers

\begin{tabular}{lllll}
\hline Physical Properties & $\mathrm{MEG}$ & $\mathrm{DEG}$ & $\mathrm{TEG}$ & TETRA EG \\
\hline Formula & $\mathrm{C}_{2} \mathrm{H}_{6} \mathrm{O}_{2}$ & $\mathrm{C}_{4} \mathrm{H}_{10} \mathrm{O}_{4}$ & $\mathrm{C}_{6} \mathrm{H}_{14} \mathrm{O}_{4}$ & $\mathrm{C}_{8} \mathrm{H}_{18} \mathrm{O}_{5}$ \\
Molecular weight, $\mathrm{g} / \mathrm{mol}$ & 62 & 106.12 & 150 & 194.2 \\
Boiling point at $760 \mathrm{~mm} \mathrm{Hg},{ }^{\circ} \mathrm{C}$ & 197 & 245 & 288 & 329 \\
Density, $(\mathrm{g} / \mathrm{cc})$ at $20^{\circ} \mathrm{C}$ & 1.115 & 1.118 & 1.125 & 1.124 \\
\hline
\end{tabular}


Stainless steel discs $10 \mathrm{~mm}$ in diameter and $3 \mathrm{~mm}$ tall and a mass close to $1 \mathrm{~g}$ were printed on ExOne's 3D printer using $316 \mathrm{~L}$ stainless steel metal powder (size of the particles is $30-50$ microns) and DEG as binder. The $3 \mathrm{D}$ parts were sintered at $1,100^{\circ} \mathrm{C}$ in $96 \% \mathrm{Ar} / 4 \% \mathrm{H}_{2}$ gas atmosphere for $30 \mathrm{~min}$. The discs were placed on a cloth or plate and $100 \mu \mathrm{L}$ of the SSN suspension were pipetted on top of it using $100 \mu \mathrm{L}$ micropipette. Total volume of the added suspension was $1 \mathrm{~mL}$. A small magnet was place underneath the plastic plate or cloth to attract the nanoparticles to the surface of the 3D print.

When soaked from the top with the nanoparticle suspension, the porous disc prints acted as a filter separating the nanoparticles from suspension. The clear fluid from the suspension was drawn out with the absorbing cloth and the nanoparticles became piled atop the printed disc. Figure 1 is a depiction of the deposition setup and the resulting separation. The 3D print was then sintered again at $1,100^{\circ} \mathrm{C}$ in $96 \% \quad \mathrm{Ar} / 4 \% \mathrm{H}_{2}$ gas atmosphere for thirty minutes.

\section{Results}

The effectiveness of the polymer solute to deliver the nanoparticles was assessed by the measuring the increase in the mass of the $3 \mathrm{D}$ parts after the application of nanoparticles and subsequent sintering. This increase in mass is shown as mass percent increase. Figure 2 shows the effect of $\mathrm{pH}$ of DEG/ $\mathrm{H}_{2} \mathrm{O}$ and $\mathrm{EG} / \mathrm{H}_{2} \mathrm{O}$ solutions on the mass percent increase of the $3 \mathrm{D}$ part (Molar ratio of $\mathrm{DEG} / \mathrm{H}_{2} \mathrm{O}$ and $\mathrm{EG} / \mathrm{H}_{2} \mathrm{O}$ is $1 / 4)$. The figure shows that change in $\mathrm{pH}$ has no effect on mass percent when nanoparticles were suspended in $\mathrm{EG} / \mathrm{H} 2 \mathrm{O}$ solution, while the change in $\mathrm{pH}$ significantly affects the mass percent when nanoparticles were suspended in $\mathrm{DEG} / \mathrm{H}_{2} \mathrm{O}$ solution. The presence of the oxygen atom in the middle of DEG molecule makes it more polar than EG (the general chemical formula of DEG is $\mathrm{R}-\mathrm{O}-\mathrm{R}$ where $\mathrm{R}$ is $\mathrm{OH}-\mathrm{CH}_{2}-\mathrm{CH}_{2}$ and the formula of EG is $\mathrm{OH}-\mathrm{CH}_{2}-$ $\mathrm{CH}_{2}-\mathrm{OH}$ ). This higher polarity can be used to explain the higher effect of $\mathrm{pH}$ on DEG than on EG.

Select samples reported in Fig. 2 were polished and imaged for density using standard metallography techniques and image analysis software. The software turns the optical microscope image into a black and white schematic (black being the pores and white being the metallic portions) and analyzes these regions for density. The samples were measured in four regions along the thickness of the discs: Top, top middle, bottom middle and bottom. Examples of the black and white images from the cross-sectioned disc samples can be seen in Fig. 3. Similar analyses were carried out on other samples where the suspension was made with DEG or $\mathrm{EG}$ at different $\mathrm{pH}$ values. As Fig. 4 shows, the density of the treated stainless steel discs increases at a $\mathrm{pH}$ of 11 for DEG, similar to what is seen in Fig. 2. The density analysis shows also an increase in density for the EG sample as well at a $\mathrm{pH}$ of 11 . The slightly higher density that can be seen in Fig. 3A than in Fig. 3B correlates to the data in Fig. 4.

Figure 2 indicates that $\mathrm{DEG} / \mathrm{H}_{2} \mathrm{O}$ suspension at $\mathrm{pH}$ 11 yields a high mass percent increase in the printed discs. The effect of $\mathrm{DEG} / \mathrm{H}_{2} \mathrm{O}$ molar ratio on the mass percent increase was then carried out at $\mathrm{pH} 11$. Figure 5 shows that DEG/water molar ratio of 1:4 gives the best mass percent value. Select samples reported in Fig. 5 were polished and imaged for density as was reported in Fig. 4. The results are shown in Fig. 6.

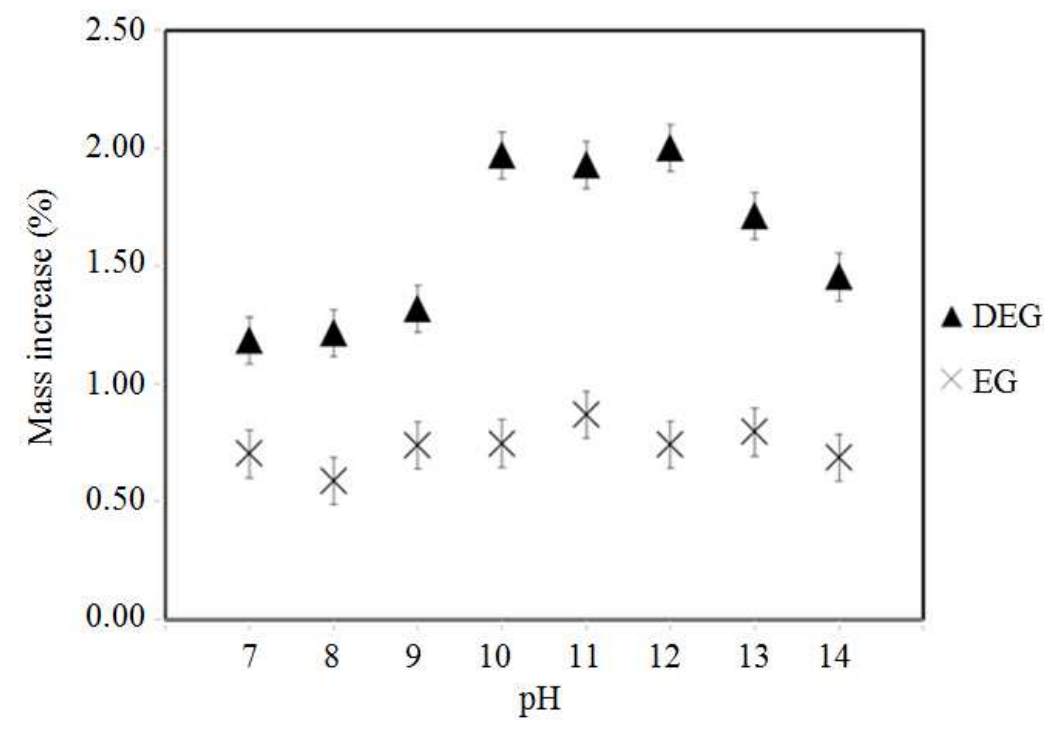

Fig. 2. Effect of $\mathrm{pH}$ on the mass increase percentage 

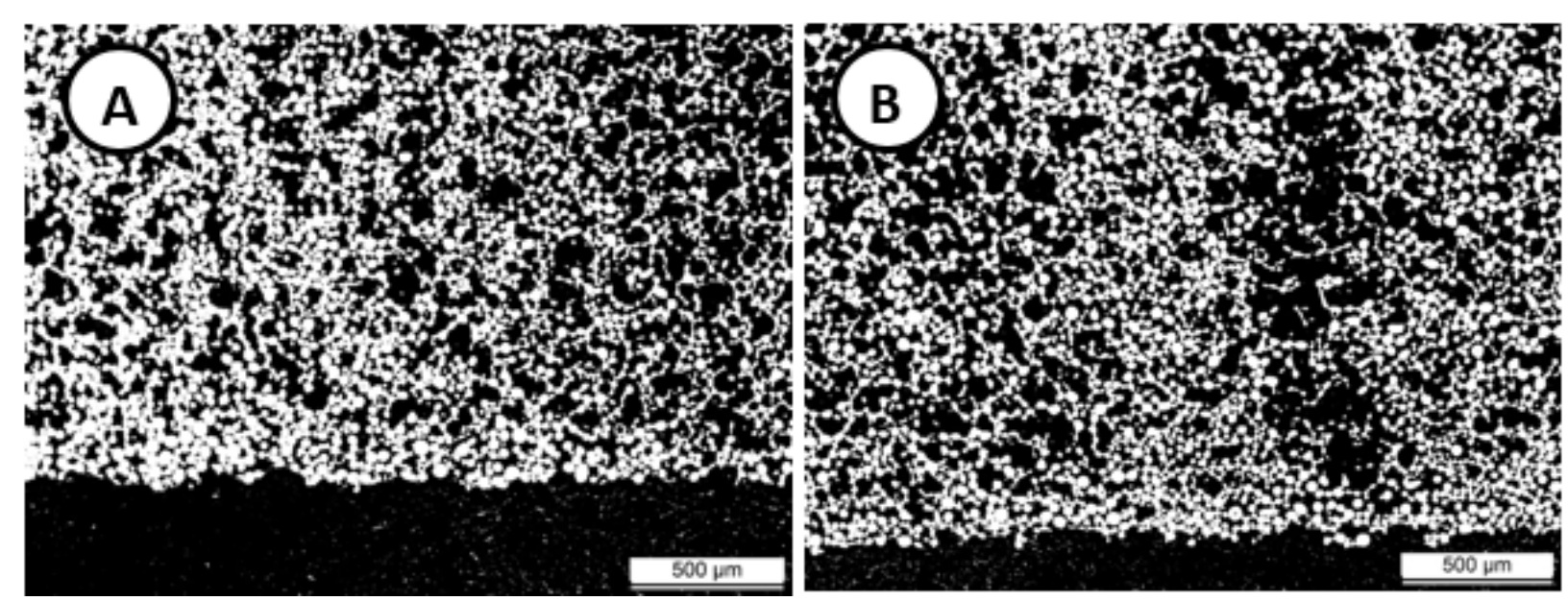

Fig. 3. Cross section of sintered disc treated with nanoparticle solution with a pH of 11 and with (A) EG/water and (B) DEG/water ratios of $1: 4$

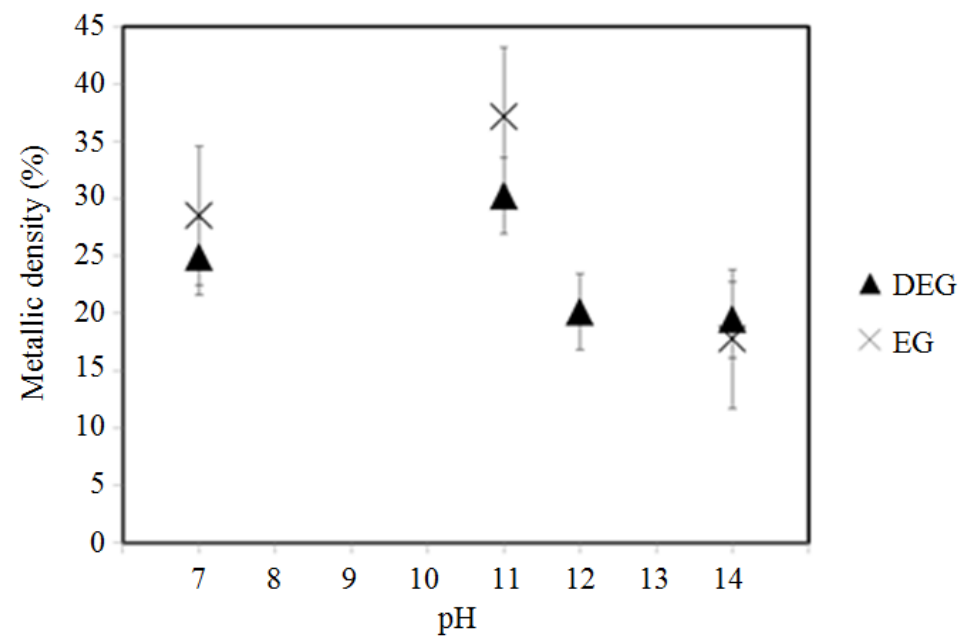

Fig. 4. Density of the sintered samples with increasing $\mathrm{pH}$ of the solutions with DEG and EG (measured optically)

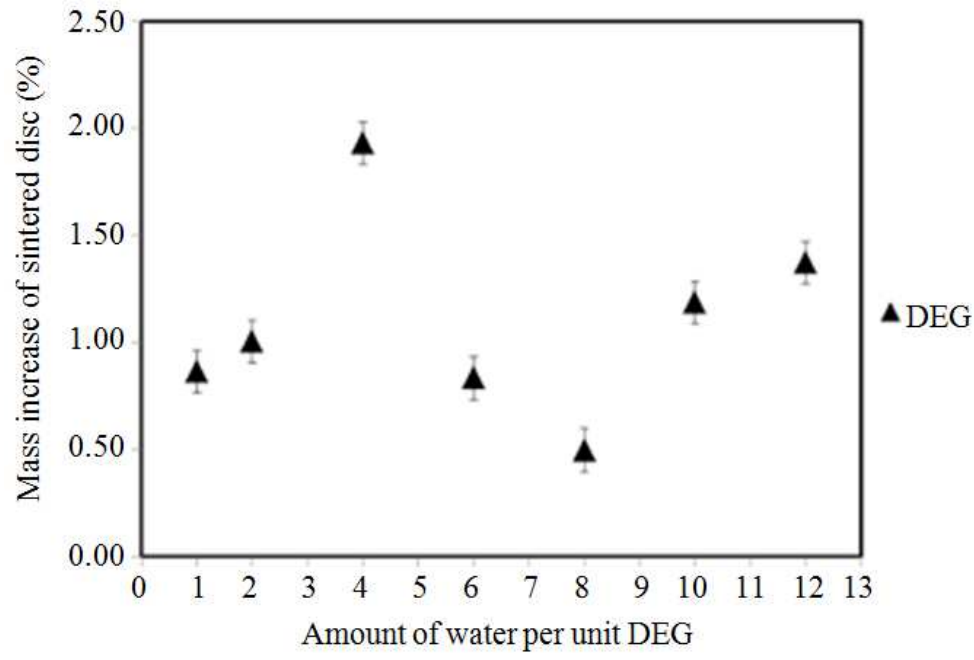

Fig. 5. Effect of DEG: $\mathrm{H}_{2} \mathrm{O}$ molar ratio on the mass increase percentage at $\mathrm{pH} 11$ 


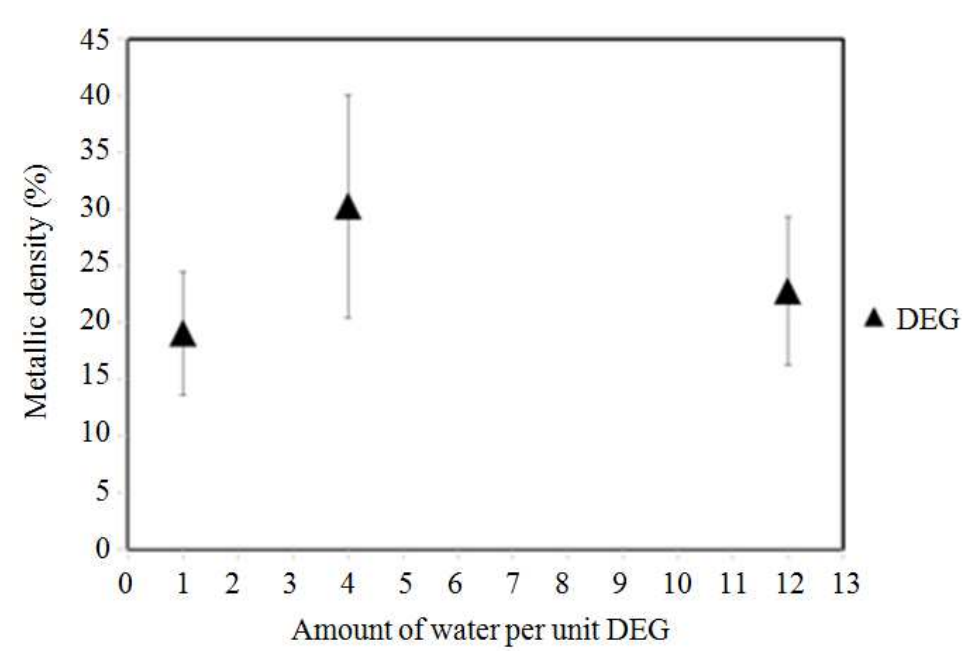

Fig. 6. Density of the sintered samples at different DEG: $\mathrm{H}_{2} \mathrm{O}$ molar ratios at $\mathrm{pH} 11$ (measured optically)

\section{Discussion}

The significant changes in the mass per cent as the DEG/ $\mathrm{H}_{2} \mathrm{O}$ molar ratio changes (Fig. 5) can be explained by the change in the pattern of hydrogen bonding between $\mathrm{H}_{2} \mathrm{O}$ and DEG molecules. Specifically, DEG molecule has three oxygen atoms that participate in hydrogen bonding with water. When an oxygen atom of DEG participates in hydrogen bonding, the partial negative charge on it is reduced which affects how DEG molecules repel each other. Such change in repulsion forces affects how the nanoparticles are dispersed in the suspension. It is hypothesized that an increase in repulsion forces between the DEG molecules will increase the dispersion of the nanoparticles in solution. Such increase in dispersion will enhance the degree of nanoparticles incorporation in the 3D part and in turn increase the 3D part mass. Figure 5 suggests that when $\mathrm{DEG} / \mathrm{H}_{2} \mathrm{O}$ molar ratio is 1:4 the repulsion forces between DEG molecules are at maximum level. The results in Fig. 5 are corroborated by optical density analysis reported in Fig. 6 .

\section{Conclusion}

A set of experiments was conducted to evaluate the effect of $\mathrm{pH}$ and molar ratio with water of DEG and EG polymers on conveying nanoparticles through sintered, additively manufactured, stainless steel discs. Through mass measurements, the solutions with DEG added the most weight at a $\mathrm{pH}$ of 11 while both DEG and EG saw an increase in density at the same $\mathrm{pH}$ as measured by optical density analysis. The higher polarity of the DEG and subsequent better dispersion and infiltration of the nanoparticles could be the cause of the increase in weight for certain $\mathrm{pH}$ levels. The optical density results, however, point to gains in metallic mass with both DEG and EG at a pH of 11 . The final analysis shows that a ratio of Water: DEG of 1:4 produces the highest weight gains as well as metallic density. Further analysis is needed to determine the effects of surface tension and viscosity of each of the mixtures on penetration of the nanoparticles into the sintered discs. This work is a step toward incorporating nanoparticles within binder jet printing fluids to increase the density and sinterability of binder jet printed parts.

\section{Acknowledgment}

The authors would like to acknowledge the Minority Serving Institutions and Partnerships Program and the Department of Energy for supporting this work.

\section{Funding Information}

The work reported here was financially supported by the National Nuclear Security Administration (NNSA)-Minority Serving Institutions and Partnerships Program.

\section{Author's Contributions}

Amelia Elliott: Participated in all experimental testing, data-analysis and contributed to the writing of the manuscript.

Sarah AlSalihi: Participated in experimental plan and testing, data-analysis and contributed to the writing of the manuscript.

Abbey L. Merriman: Participated in experimental plan, data-analysis and contributed to the writing of the manuscript. 
Mufeed M. Basti: Participated in experimental plan, data-analysis and contributed to the writing of the manuscript.

\section{Ethics}

All rights reserved. No part of this publication may be reproduced or transmitted in any form or by any means, electronic or mechanical, including photocopy, or any information storage and retrieval system, without permission in writing from the publisher or authors.

\section{Reference}

Allen, S.M. and E.M. Sachs, 2000. Three-dimensional printing of metal parts for tooling and other applications. Met. Mater., 6: 589-594.

DOI: $10.1007 / \mathrm{BF} 03028104$

Bai, J.G., K.D. Creehan and H.A. Kuhn, 2007. Inkjet printable nanosilver suspensions for enhanced sintering quality in rapid manufacturing. Nanotechnology, 18: 185701-185701. DOI: 10.1088/0957-4484/18/18/185701

Crane, N.B., J. Wilkes, E. Sachs and S.M. Allen, 2005. Improving accuracy of powder sintering-based SFF processes by metal deposition from nanoparticle dispersion.

Cutler, I.B., C. Bradshaw, C.J. Christensen and E.P. Hyatt, 1954. Sintering of alumina at temperatures of $1400^{\circ} \mathrm{C}$ and below. J. Am. Ceram. Soc., 40: 134-139. DOI: $10.1111 /$ j.1151-2916.1957.tb12589.x

Ekka, P., 2012. Effect of binders and plasticisers on alumina processing. BTech Thesis, National Institute of Technology Rourkela.

Halidi, S.N.A.M. and J. Abdullah, 2012. Moisture effects on the ABS used for fused deposition modeling rapid prototyping machine. Proceedings of the IEEE Symposium on Humanities, Science and Engineering Research, Jun. 24-27, IEEE Xplore Press, Kuala Lumpur, pp: 839-843. DOI: 10.1109/SHUSER.2012.6268999
Hockaday, L.A., K.H. Kang, N.W. Colangelo, P.Y.C. Cheung and B. Duan et al., 2012. Rapid 3D printing of anatomically accurate and mechanically heterogeneous aortic valve hydrogel scaffolds. Biofabrication, 4: 035005-035005. DOI: 10.1088/1758-5082/4/3/035005

Khaing, M.W., J.Y.H. Fuh and L. Lu, 2001. Direct metal laser sintering for rapid tooling: Processing and characterisation of EOS parts. J. Mater. Process. Technol., 113: 269-272. DOI: 10.1016/S0924-0136(01)00584-2

Koparde, V.N. and P.T. Cummings, 2008. Sintering of titanium dioxide nanoparticles: A comparison between molecular dynamics and phenomenological modeling. J. Nanoparticle Res., 10: 1169-1182. DOI: $10.1007 / \mathrm{s} 11051-007-9342-3$

Lee, E.S., H.J. Shin, K. Na and Y.H. Bae, 2003. Poly(Lhistidine)-PEG block copolymer micelles and $\mathrm{pH}$ induced destabilization. J. Control. Release, 90: 363-374. DOI: 10.1016/S0168-3659(03)00205-0

Leukers, B., H. Gülkan, S.H. Irsen, S. Milz and C. Tille et al., 2005. Hydroxyapatite scaffolds for bone tissue engineering made by 3D printing. J. Mater. Sci. Mater. Med., 16: 1121-1124. DOI: $10.1007 / \mathrm{s} 10856-005-4716-5$

Rahaman, M.N., 2003. Ceramic Processing and Sintering. 2nd Edn., CRC Press, Boca Raton, FL., ISBN-10: 0824709888, pp: 875.

Silva, D.N., M. Gerhardt de Oliveira, E. Meurer, M.I. Meurer and J.V. Lopes da Silva et al., 2008. Dimensional error in selective laser sintering and 3D-printing of models for craniomaxillary anatomy reconstruction. J. Cranio-Maxillofacial Surg., 36: 443-449. DOI: 10.1016/j.jcms.2008.04.003 